\title{
Future Technologies: The Matter of Emergent Ethical Issues in Their Development
}

\author{
Bernd C. Stahl, Simon Rogerson and Kutoma J. Wakunuma \\ Centre for Computing and Social Responsibility \\ De Montfort University \\ The Gateway, Leicester, LE1 9BH, UK \\ bstahl@dmu.ac.uk, $\underline{\operatorname{srog} @ \text { dmu.ac.uk, kutoma@dmu.ac.uk }}$
}

\begin{abstract}
Ethical issues in technologies are usually identified when a technology has already been developed. Little consideration is given to ethical issues as they emerge from technologies being developed. This can be disadvantageous on a number of fronts, not least because an opportunity to avoid or correct any pitfalls as future technologies and applications come to life could have been avoided. Needless to say, a better understanding of ethical issues as future technologies emerge can be beneficial to influencing the design and eventual implementation of future technologies. Arguably, projecting any future, let alone that of technologies is challenging. However, borne out of a project with a mandate to look at emerging technologies and ethical issues in ICT applications (ETICA) especially in Europe, this paper outlines how the ETICA project has began carrying out this mandate by initially developing a conceptual framework of future technologies with a view to outlining subsequent emerging ethical issues. This outline is undertaken by looking at likely future technological developments that are expected to materialise in the next 10 to 15 years in Europe. Although a European landscape and perspective offers a starting point in projecting future technologies and their ethical issues, the ETICA project hopes that its findings will resonate to some degree at a global level where good practice might be learnt and shared because future technologies and their ethical issues will no doubt be cross-cutting just as present and already existing technologies are. This paper and ETICA's work is relevant for the conference because it not only aims to discuss likely future technological development but goes a step further to look at the subsequent ethical issues that are likely to arise as well. The awareness of ethical issues as future technologies are being developed is equally important because developers become alert and sensitive to users needs not only as they plan the technologies but also during the process of development right up to implementation. Such awareness has the potential to avoid or lessen major ethical pitfalls when a technology is fully developed and in operation.
\end{abstract}

Keywords-future and emerging technologies; ethical issues; EU; ETICA

\section{INTRODUCTION}

Technology has become an important facet in today's everyday life whether it is in the area of health, education, business, leisure and other varied areas. Because technology has become a vital part of everyday life, new and emerging technologies are continuously being developed. Future technologies are being developed to better current ones due to the ever increasing demand of for instance even quicker and faster technologies; technologies that can manage and store our huge masses of data as well as for technologies that can play an important role in state of the art health care among other areas of demand. For instance the need to drive technological innovation in the European Union (EU) is recognised in the European Commission's (EC) communication titled "A strategy for R\&D and innovation in Europe: Raising the Game", in which the communication highlights that Europe should be in the forefront in developing ICT-based personalised health systems to "significantly improve diagnosis and treatment of diseases and prolong the independence of elderly people" (European Commission, 2009, p. 3). In other words, there is a race for more innovative future technologies. However, with new and future technologies come pitfalls that may compromise the benefits that future technologies promise. To avoid these, it is important not to wait until the technologies come to their full existence, but to be able to tackle the ethical pitfalls as they arise. This calls for a projection of what future technologies may be and how to deal with their subsequent ethical issues. Admittedly, the future is unknown and therefore difficult and challenging to project. However, looking at technology roadmaps outlined by the EU for instance can help to have a sense of what future technologies might materialise. Armed with this knowledge, the possibility exists to identify likely ethical pitfalls as they arise. Knowing what ethical issues may arise from future technologies reduces the likelihood of technologies that may have negative consequences on society. By knowing the pitfalls well in advance, the design of future technologies may be such that the problems are rectified or lessened and that those technologies that have little to no benefit to society avoided. With this in mind, the ETICA project has embarked on investigating future and emerging technologies and their ethical issues.

This section will be followed by the methodology section, which will lead to the conceptual framework of the paper which outlines some of the EU's ICT undertakings. This is followed by a section highlighting future technological areas as they relate to the EU's FP7 ICT 
challenges. An ethical issues section follows immediately after. Before the conclusion, this section identifies some of the ICT ethical issues.

\section{Research Method}

This paper is of a conceptual nature and provides a starting point in examining future emerging technologies. It provides an analysis of likely developments of future technologies and their application areas in Europe. This is done through a content analysis of a range of sources, particularly of EU documents related to information communication technologies. This has given a flavour of likely technologies that are to be developed in the next 10 15 years. Although it may be beneficial to investigate the global phenomenon of future technologies and ethics, at this point however, it is beyond the scope of this paper to do so. Europe has been chosen as a starting point towards this roadmap due to a number reasons which include the fact that the EU is one of the most important economic and political entities and that its research policy has the potential of shaping future technical and economic standards. In addition, the European view of technologies and indeed future technologies at that is important because it is developed in intercultural discourses with scientists and researchers worldwide. It shows the way that policy makers perceive the role of technology. At the same time Europe has the potential to shape future technology developments. An additional reason for concentrating on Europe is because part of the remit of the ETICA project is to provide a basis for European policy development on emerging future technologies and ethical issues. While this paper and the underlying project are thus concentrating on a particular region, we believe that our findings should be of interest more generally and are likely to be transferable at least to a considerable degree.

\section{Conceptual Framework}

\section{An Overview}

The EU has always been eager to promote research and development through its framework programmes. The two main aims of the framework programme, is "to strengthen the scientific and technological base of the European industry [and] to encourage its international competitiveness, while promoting research that supports EU policies" (European Commission, 2007, p.7). The most recent EU framework programme is the 7th framework programme (FP7) which runs from 2007 to 2013 and whose core area is the Cooperation programme, which is used to fund collaborative projects involving partners from some European Member States. The previous programme was the FP6 programme which ran from 2002 to 2006. Both these programmes have supported research into innovative and future technologies; with the FP6 programme having had a specific technology thematic area known as Information
Society Technologies (IST) while the FP7 has a thematic area known as Information and Communication Technologies (ICTs). The ICT programme under the current FP7 is part of ten thematic sub-programmes of the Cooperation programme and has the largest budget over the lifetime of the FP7 ${ }^{\mathrm{i}}$. ICT research has been identified as one of the three pillars of the "i2010 - A European Information Society for growth and employment" initiative of the European Commission. The i2010's renewed Lisbon agenda relies heavily on ICT to realise efficiency and economic gains $^{\text {ii. }}$ This shows the importance which the EU attaches to technologies.

In addition the importance of technology development and innovation to the EU is further highlighted in the EU's Future and Emerging Technologies (FET) activities programme which falls within the ICT programme. The FET "serves as an essential pathfinder for identifying and shaping radically new information technologies. FET supports research into new and emerging scientific ideas and thereby acts as a catalyst for the creation and development of new visions for information and communication technologies" (European Commission, March 2009). This shows that the EU is always on the lookout for new and innovative technologies which they are keen to support. FET activities command a funding of about $€ 100$ million per year. Such activities are intended to be roadmaps to future technologies and application areas. The EU highlights such activities and gives an indication of what sort of technological developments they view as realistic and important in their ICT Calls. In particular, the ICT Call that shows where EU policy makers think research in technologies should concentrate on can be seen in the ICT Call 4 (European commission, 2008a) which outlines the challenges that they hope technologies can overcome and consequently the technologies and applications they hope to see developed to overcome such challenges.

These Calls show the technological trends that might be developed, the technology application areas and the challenges that need to be overcome including the type of artefacts that may be incorporated in the developed of future technologies. With these come consideration of ethical issues in terms of what these may be and how they may be tackled. To overcome ethical issues that will be identified, governance structures will also have to be considered with a view to developing structures within which ethical issues can identified and rectified. In recognising the above categories that might exist as technologies are developed, the ETICA project has come up with a tentative framework of analysis within which emerging and future technologies and ethical issues can be undertaken. This framework is highlighted in Table 1, which at present highlights a summary of emerging EU ICT landscape. This was developed by looking at the EU technological trends, their application areas including their challenges as outlined within the seven ICT challenges revealed by the EU. The 
development also took into consideration the purpose and policy aim within which the application areas were being considered as were as the possible governance structures and ethical issues. By applying this framework to the work in question, the table provides a high level summary of the landscape of emerging ICT ethics and can potentially be used as a basis for further research. Therefore, in looking at future technologies and their subsequent ethical issues, the project will look at trends, policy aim, applications, artefacts, ethical issues and governance structures. This is by no means a conclusive framework but a beginning nonetheless which will be developed upon.

\section{Future technologies}

\section{A. Challenges}

The FP7 ICT Call 4 provides a roadmap of where future technological developments are going. ICT Call 4 published on 19th November 2008 (EC, 2008a) explains in most detail the aims and objectives of the ICT work programme and thereby gives an exact view of what European policy makers believe to be innovative, realistic and future technological developments that research should aim for. Call 4 outlines seven main challenges which the EU views as relevant and which future technological developments and applications should be aiming for in the next $10-15$ years. These challenges are divided into two groups: "overcoming technology roadblocks and reinforcing Europe's industrial strengths" and "seizing new opportunities and applying ICT to address Europe's socioeconomic challenges". The first group contains those challenges which can be seen as technological in nature, which seems to imply that their social and economic context is less important or maybe unproblematic. These include: "pervasive and trustworthy network and services infrastructure"; "cognitive systems, robotics and interaction" and "electronic components and systems". These are seen to be crucial for the development of the next generation of technologies and therefore as a central basis for further innovation in products and services. It is interesting to note that for all of the three technical challenges the work programme is silent on their expected consequences and link to policy goals. This implies a pervasive belief that technological progress is desirable because of its knock-on effects, the hope that it will lead to successful products, higher competitiveness and thereby to well-being and employment.

The second group of challenges, the socio-economic ones, are more immediately and more visibly linked to the European policy goals. The four challenges meant to address "Europe's socio-economic challenges" are aimed at specific areas where technology is perceived to have a crucial role. They include: "libraries and digital content"; "Towards sustainable and personalized healthcare"; "ICT for mobility, environmental sustainability and energy efficiency"; and "ICT for independent living, inclusion and governance".

\section{B. Future and Emerging Technologies (FET) Activities}

A separate part of the Call 4 document under challenges is that of "future and emerging technologies" (FET). Given that the aim of the paper is to provide a framework for the investigation of ethical issues of emerging technologies, these emerging technologies as outlined by the call document are of particular interest. As they are at a more exploratory stage, their actual conceptual and physical form are currently still uncertain, but the technologies suggested render it clear which way the development is expected to take. For instance the FET research roadmaps document (European Commission, March 2009) states that it operates two complementary schemes whose aim is to "nurture new and emerging fundamental trends in future information technologies". These include the bottom-up and deadlinefree FET Open scheme where new ideas and opportunities are picked up whenever they arise and the FET Proactive which "nurtures new ideas and opportunities picked up in promising domains." (European Commission, 2009). Currently under FET, the first set of such emerging technologies has to do with high speed data processing and it is listed under "Concurrent Tera-Device Computing." The next set of technologies is based on "quantum information foundations and technologies." "Molecular-scale devices and systems" are suggested as a further important research area. Another predominantly technical area is that of "biochemistry-based information technology." The attempt to use cross-disciplinary research in order to improve ICTs is furthermore developed in the "brain-inspired ICT." In addition to these technical challenges, there are also application-driven emerging technologies. The first one is "human-computer confluence" which explores new modalities for individual and group perception, actions and experience in augmented, virtual spaces. There is also an area of self-awareness in autonomic systems, which aims at an improvement of the interaction between computing artefacts and their environment. Environmental concerns are reflected in the research towards zero-power ICT. To some degree one can see reflected the distinction between purely technical considerations, which at this stage are not yet application-oriented and those that are specific to particular issues.

Together these challenges represent the applications that the European Commission sees as central to advance its policy agenda. They set the boundaries for the type of research that will be funded under the current FP7. They are therefore likely to have an influence on the technologies that will become viable and wide-spread in the next decade. It is clear that this is not an exclusive list and that there are other development agendas from private organisations, nation states, NGOs etc. that are similarly worth exploring. For our purposes, however, the EU policy is of central interest and 
we will therefore concentrate on these applications. The question that remains is what ethical issues might these potential technologies and applications raise.

\section{v. ETHICAL ISSUES}

With new and potential future technologies come ethical concerns. Research in ICT ethics is often multidisciplinary and attempts to come to a broad understanding of the subject at hand. Much research is focused on specific issues and problems. Among the most prominent ones one can find issues such as privacy (Brown, 2000; Introna, 2003), intellectual property (Burk, 2001; Syme and Camp, 2002), access and digital divides (Rooksby and Weckert, 2006), data quality (George, 2002). However, these issues and problems often come to light after a technology has been developed. Had such issues and problems been identified as the technologies are developed, the likelihood is that most of such problems would perhaps have been tackled with from the onset. In light of this, there is much to be said in identifying ethical issues as they emerge as technologies are developed, not least because relevant policy can be put in place to deal with ethical pitfalls well in advance of the emerging technologies.

The strategic technological areas of interests outlined above will no doubt bring about ethical issues as they are developed. Some of the likely ethical issues may be found in for instance, the Pervasive and trustworthy network and service infrastructure challenge which is concerned with the future of the internet. The Call outlines areas where the internet might be improved and RFID technologies are some of the technologies identified as being able to play a part in the aforementioned improvement. This would be through sensory applications, tags and actuators. Such applications, according to the Call can "provide physical world information enabling new classes of applications combining virtual and physical world information". Obvious ethical issues to be concerned about would be aspects of privacy, incorporation of sensors and tags to individuals and their surrounding environments. As the technologies develop, there is need to be aware of other ethical issues which are not visible at present. Similarly, the Cognitive Systems, Interaction, Robotics challenge as well as the "Towards sustainable and personalised healthcare" challenge all raise their own potential ethical issues. For example, the personalised health care challenge identifies personal health systems (PHS) as some of the systems that can play a major role in health care. These will include wearable, portable or implantable systems. The idea is to assist health carer's with monitoring of patients and improve on their knowledge of diagnostic data. In relation to the Independent living, Inclusion and Governance challenge, the Call's view is such that some aspects of research will look into and include the development of robotics and new human computer interfaces based on brain neurocomputer interaction. Ethical issues that may arise from all the outlined future technologies combined may include issues of:
- data collection

- privacy

- $\quad$ security

- trust

- wearable systems

- ever present technologies due to their embedded nature

- isolation of patients due to little or no human contact because technologies take over

- $\quad$ over dependency on technologies like robots

Several questions arise in relation to how the above ethical concerns might be dealt with as the technologies are being developed? For instance, what happens to all the patient data that is collected and how can we ensure that as patient data is exchanged within EU member states for instance that measures are put in place to ensure its security. How can patients be involved in the design process knowing that such technologies will exist to serve and service them? What form can wearable technologies take and how do we guard against misuse of information. How far can we go in terms of wearable technologies and to what extent can and should they be ethical. Questions also arise as to whether users will want technology to be ever present and if not how do we ensure that they are not left with no choice but to deal with the technologies they have been dealt with. Additionally, although the hope is that future and innovative technologies will bring positive developments as they emerge so much so that there will be less isolation of people, the opposite may be true. The fact that technologies are being developed to assist with health aspects, such as the monitoring of patients, may also lead to isolation. This is because patients can be monitored remotely without necessarily having to meet patients face to face. This is a downside because some patients yearn for human contact and if that ceases to exist, the downside is that it may also contribute to a patients continued underlying condition. Finally, the temptation to succumb to the ever present embedded technologies including robots may lead to over dependency on such systems even for the most mundane of things. How can we then guard against such possibilities thereby ensuring that we do not become victims of the very technologies we are developing that are intended only to improve and better our lives?

\section{CONCLUSION}

This paper has outlined some of the foreseeable future and emerging technologies in Europe. However, the premise of the paper was not only to outline such technologies but to show that with technological developments exists a need to be on the lookout for ethical issues that may arise as well. This is a work in progress and as such a starting point in considering such issues. A possible framework has been explored and no doubt needs to be developed further. Ethical issues are usually only considered after a technology has been in place and understandably so because it is easier to 
see what ethical issues have materialised with a tangible technology in hand. It is however harder to project ethical issues as they arise from emerging technologies because the very nature of projecting something in the future is difficult. However, there is value in looking at ethical issues as they arise from technologies being developed rather than wait until they are fully developed because among other reasons, effective policies may be put in place to counter unwanted ethical fallouts.

\section{REFERENCES}

[1] European Commission, (2009). A Strategy for ICT R\&D and Innovation in Europe: Raising the Game. Communication from the Commission to the European Economic and Social Committee and the Committee of the Region. Retrieved July 9, 2009, from http://eurlex.europa.eu/LexUriServ/LexUriServ.do? uri=COM:2009:0116:FIN:EN:PDF.

[2] European Commission, (March 2009). FET Research Roadmaps: Pointing the Way to Future ICTs. Retrieved July 9, 2009, from ftp://ftp.cordis.europa.eu/pub/fp $7 /$ ict/docs/fet-proactive/press$\underline{10 \text { en.pdf }}$

[3] European Commission. (2008a). Work Programme 2009; Cooperation; Theme 3, Information and Communication Technologies (European Commission C(2008)6827 of 17 November 2008). Retrieved November 26, 2008, from http://cordis.europa.eu/fp7/dc/index.cfm? fuseaction=UserSite.FP7DetailsCallPage\&call_id=185.

[4] Brown, W. S. (2000). Ontological Security, Existential Anxiety and Workplace Privacy. Journal of Business Ethics, 23(1), 61-65.

[5] Burk, D. L. (2001). Copyrightable functions and patentable speech. Communications of the ACM, 44(2), 69-75.

[6] Introna, L. D. (2003). Workplace Surveillance 'is' Unethical and Unfair [Opinion]. Surveillance \& Society, 1(2), 210-216.

[7] Syme, S., and Camp, L. J. (2002). The Governance of Code: Open Land vs. UCITA Land. ACM SIGCAS Computers and Society, 32(3).

[8] Rooksby, E., and Weckert, J. (2006). Information Technology and Social Justice (p. 292). Information Science Publishing.

[9] George, R. T. D. (2002). The Ethics of Information Technology and Business (p. 304). WileyBlackwell.

Table 1: Summary of Emerging EU ICT Research Landscape

\begin{tabular}{|c|c|c|c|c|c|}
\hline Trends & Purpose/Policy Aim & Applications/Challenges & Artefacts & Ethical Issues & $\begin{array}{l}\text { Governance } \\
\text { Structure }\end{array}$ \\
\hline \multirow{2}{*}{$\begin{array}{l}\text { ever-increasing } \\
\text { computational } \\
\text { power plus } \\
\text { decreasing size and } \\
\text { cost }\end{array}$} & \multirow{3}{*}{ economic growth } & network infrastructure & physical artefacts & research process & \multirow{2}{*}{$\begin{array}{l}\text { external } \\
\text { governance }\end{array}$} \\
\hline & & \multirow[t]{2}{*}{ cognitive systems, robotics } & processes and procedures & $\begin{array}{l}\text { informed consent } \\
\text { legal compliance }\end{array}$ & \\
\hline \multirow{3}{*}{$\begin{array}{l}\text { advances enabling } \\
\text { new types of } \\
\text { interfaces }\end{array}$} & & & IPv6 & research content & ethical review as \\
\hline & \multirow{3}{*}{ employment } & \multirow{2}{*}{ components, systems, engineering } & $\begin{array}{l}\text { concurrent terra-device } \\
\text { computing }\end{array}$ & privacy/data protection & $\begin{array}{l}\text { part of scientific } \\
\text { review }\end{array}$ \\
\hline & & & $\begin{array}{l}\text { quantum information } \\
\text { foundations and technologies }\end{array}$ & ICT implants/wearable computing & $\begin{array}{l}\text { external advisory } \\
\text { board }\end{array}$ \\
\hline \multirow{3}{*}{$\begin{array}{l}\text { ability to be } \\
\text { connected } \\
\text { anywhere, anytime } \\
\text { with services on } \\
\text { demand }\end{array}$} & & digital libraries and content & \multirow{2}{*}{$\begin{array}{l}\text { bio-chemistry-based } \\
\text { information technology }\end{array}$} & e-health related issues & \multirow{3}{*}{$\begin{array}{l}\text { internal } \\
\text { governance }\end{array}$} \\
\hline & \multirow{3}{*}{$\begin{array}{l}\text { demographic challenges } \\
\text { solutions }\end{array}$} & & & nano- and bio- electronics & \\
\hline & & healthcare & human-computer confluence & research on animals & \\
\hline \multirow{3}{*}{$\begin{array}{l}\text { creation of virtual } \\
\text { places, service } \\
\text { providers and } \\
\text { products }\end{array}$} & & sustainability & $\begin{array}{l}\text { self-awareness in autonomous } \\
\text { systems }\end{array}$ & $\begin{array}{l}\text { research involving developing } \\
\text { countries }\end{array}$ & \multirow{2}{*}{$\begin{array}{l}\text { work package on } \\
\text { ethics }\end{array}$} \\
\hline & \multirow{2}{*}{ social/political inclusion } & \multirow{2}{*}{ inclusion } & $\begin{array}{l}\begin{array}{l}\text { molecular-scale devices and } \\
\text { systems }\end{array} \\
\end{array}$ & \begin{tabular}{|l|} 
research involving human \\
embryos or foetuses
\end{tabular} & \\
\hline & & & brain-inspired ICT & \begin{tabular}{|l|}
$\begin{array}{l}\text { dual use (military or terrorist } \\
\text { applications) }\end{array}$ \\
\end{tabular} & $\begin{array}{l}\text { informed consent } \\
\text { procedures }\end{array}$ \\
\hline $\begin{array}{l}\text { intuitive, sensitive } \\
\text { and responsive }\end{array}$ & intelligent environments & AmI applications & $\begin{array}{l}\text { Smart "intelligent" } \\
\text { technologies }\end{array}$ & $\begin{array}{l}\text { autonomy/privacy/data protection/ } \\
\text { trust }\end{array}$ & $\begin{array}{l}\text { operational } \\
\text { validation }\end{array}$ \\
\hline
\end{tabular}


${ }^{\mathrm{i}}$ http://cordis.europa.eu/fp7/budget en.html

ii http://ec.europa.eu/information_society/eeurope/i2010/introduction/index_en.htm 